\title{
Recombinant tissue plasminogen activator in the treatment of suprachoroidal hemorrhage
}

\author{
Nancy Kunjukunju' \\ Christine R Gonzales ${ }^{2}$ \\ William S Rodden² \\ 'Ochsner Medical Center, New \\ Orleans, Louisiana; ${ }^{2}$ Retina and \\ Vitreous Center of Southern Oregon, \\ Ashland, Oregon, USA
}

This article was published in the following Dove Press journal:

Clinical Ophthalmology

3 February 2011

Number of times this article has been viewed

Background: Suprachoroidal hemorrhages are a vision-threatening complication, and poor visual outcome is correlated with increasing hemorrhage complexity. The recommended time of surgical drainage is 10-14 days after the hemorrhage begins to liquefy. We describe a case in which recombinant tissue plasminogen activator ( $\mathrm{r}-\mathrm{tPA}$ ), alteplase, is injected within the suprachoroidal space before surgery to assist in the drainage of an organized clot prior to liquefaction. This is a report of a technique in which r-tPA is used in the intrachoroidal space to target the organized clot of suprachoroidal hemorrhage prior to drainage.

Case report: A 62-year-old male presented 12 days after retinal detachment repair with sudden ocular pain and vision loss after a Valsalva maneuver. Vision was light perception only, and intraocular pressure was $43 \mathrm{mmHg}$. Diagnosed with hyphema and suprachoroidal hemorrhage, the patient underwent surgery the following day. An injection of r-tPA $100 \mu \mathrm{g}$ was given intracamerally, and an additional dose of r-tPA $100 \mu \mathrm{g}$ was injected into the suprachoroidal space prior to surgery. Liquified by r-tPA, the clot was expressed through the sclerotomies. Best corrected vision in the eye eight months after the drainage procedure was 20/40.

Conclusion: To the author's knowledge, this is the first reported case in which r-tPA was successfully injected in the suprachoroidal space to liquefy and drain a suprachoroidal hemorrhage prior to natural dissolution.

Keywords: tPA, suprachoroidal hemorrhage, vision loss

\section{Introduction}

Suprachoroidal hemorrhage is a vision-threatening complication associated with certain surgical procedures, such as cataract extraction, glaucoma filtering surgery, penetrating keratoplasty, and retinal detachment repair. ${ }^{1-4}$ Suprachoroidal hemorrhage has also been reported to occur with penetrating trauma, choroidal melanoma, and may even occur spontaneously from corneal perforation secondary to infection. 5 Generally, suprachoroidal hemorrhage has a guarded prognosis and poor visual outcome is correlated with increasing hemorrhage complexity. ${ }^{6}$ In one study, only $35 \%$ of eyes had a final visual acuity of at least $5 / 200 .{ }^{6}$ Visual rehabilitation is often limited and severe visual loss may be the final result. Surgical drainage is a topic of much controversy, but may be advocated in cases where suprachoroidal hemorrhage is accompanied by retinal detachment, central choroidal apposition, retinal or vitreous incarceration in the surgical wound, persistent flat chamber, extreme pain, uncontrolled intraocular pressure, or inability to reposition intraocular contents. ${ }^{7-9}$ A suggested time for surgical drainage is said to be 10-14 days when the hemorrhagic clot begins to liquefy. ${ }^{10}$ If adequate thrombolysis could be achieved earlier, retinal complications may

Correspondence: Nancy Kunjukunju I5I 4 Jefferson Highway, New Orleans, LA 70I2I, USA

$\mathrm{Tel}+|9| 7670989 \mid$

Fax +I 5048425240

Email nkunjukunju@gmail.com 
be prevented or reduced. Pharmacologic clearance of the clot could accelerate clearance of the hemorrhage and potentially reduce serious retinal complications. We describe the use of the recombinant tissue plasminogen activator (r-tPA), alteplase, injected within the suprachoroidal space prior to surgery to assist in drainage of suprachoroidal hemorrhage.

\section{Case report}

A 62-year-old male underwent vitrectomy for retinal detachment repair. Twelve days after surgery, the patient attended the clinic with severe eye pain and vision loss immediately after an episode of vomiting. At the time of examination, vision was light perception only and intraocular pressure was $43 \mathrm{mmHg}$. The patient had a dense anterior chamber hyphema and massive hemorrhagic choroidal detachment detected via B-scan ultrasonography. The patient was scheduled for surgical drainage the following day.

At the beginning of surgery, r-tPA $100 \mu \mathrm{g}$ was injected into the anterior chamber and an additional r-tPA $100 \mu \mathrm{g}$ was injected into the suprachoroidal space. Prior to performing conjunctival peritomy, a period of 15 minutes was allotted for clot dissolution with r-tPA. Conjunctival peritomy was then performed and the rectus muscles were isolated. An anterior chamber maintainer was placed inferotemporally. Anterior chamber washout was performed. Posterior sclerotomies were created in two quadrants to drain the hemorrhage. Approximately 45 minutes passed from the time of the initial injection of the r-tPa and actual drainage. Liquified by the r-tPA, the previously organized clot was expressed through the sclerotomies. A light pipe and vitrector were inserted for intravitreal washout. Liquid perfluorocarbon was used to assist in the drainage process and flatten choroidals from within the eye. The sclerotomies were closed with interrupted 7-0 Vicryl sutures. Two air-fluid exchanges were performed, followed by an air-silicone exchange. 5000-Centistoke silicone oil was used at the end of the procedure. The oil was removed five months after the procedure. Best corrected vision in the eye eight months after the drainage procedure and three months after oil removal was 20/40.

\section{Discussion}

Generally, suprachoroidal hemorrhage is associated with poor vision. Poor outcome has been associated with retinal detachment at presentation, vitreous incarceration in the wound, and a $360^{\circ}$ hemorrhage. ${ }^{6}$ As the complexity of the suprachoroidal hemorrhage increases, any associated retinal detachment is more difficult to fix. ${ }^{11}$ In addition, as the severity of the hemorrhage increases, it is associated with greater anatomic disruption, inflammation, and release of proliferative vitreoretinopathy precursor cells. ${ }^{11}$ Hypotony is a significant problem and also appears to be associated with the degree of hemorrhage complexity, and may be due to hemorrhagic necrosis of the ciliary body. ${ }^{12}$ Hypotony and increased ciliary body atrophy has been noted at 14 days in conjunction with hemorrhagic detachment of the ciliary body. Indications for surgery may include marked retinal apposition due to massive choroidal detachment, involvement of the macular area by hemorrhage, retinal detachment, central choroidal apposition, retinal or vitreous incarceration in the wound, persistent flat chamber, extreme pain, and uncontrolled intraocular pressure. ${ }^{13}$

There is some disagreement as to when surgery should be performed. Some authors suggest waiting 10-14 days for the clot to liquefy prior to any surgical intervention, ${ }^{10,14}$ whereas others advocate early surgical intervention for better anatomic and visual outcome. ${ }^{13}$ While waiting for the clot to liquefy, tractional retinal detachment may occur. Where there is vitreous incarceration, waiting for spontaneous resolution could result in the formation of giant retinal tears and rhegmatogenous detachment secondary to traction on the incarcerated vitreous. In cases of extensive hemorrhage, patients have sustained vision loss from chronic atrophy or phtisis bulbi in the absence of prompt surgical intervention. As such, prompt drainage may provide the best chance for maintaining useful vision. ${ }^{15}$ However, when early drainage is performed, repeated surgical procedures are often necessary to drain the hemorrhage.

r-tPA is a naturally occurring thrombolytic enzyme which activates fibrin-bound plasminogen to plasmin. ${ }^{16}$ When infused intravenously, the half-life of r-tPA is a few minutes. r-tPA has a high specific affinity for fibrin and enhances the binding of plasminogen to a fibrin clot. The enzyme acts selectively without inducing a systemic coagulation response. ${ }^{16}$ r-tPA has been effective in clearing hyphema, intraocular fibrin, vitreous hemorrhage, retinal vein occlusion, and subretinal hemorrhage. ${ }^{17-20}$ In an experimental study involving rabbits, conducted by Kwon et al, suprachoroidal hemorrhages were created in rabbit eyes and randomized for treatment with a surgical sponge soaked with r-tPA. Clot dissolution started within minutes in the treated eyes, whereas days passed prior to the clot dissolving in the control eyes. ${ }^{21}$ Another study, conducted by Liu et al, evaluated the use of intravenous r-tPA in rabbits with suprachoroidal hemorrhages and found that intravenous r-tPA accelerated the clearance of the suprachoroidal hemorrhage when compared with control eyes. ${ }^{22}$

In our case, r-tPA $100 \mu \mathrm{g}$ was injected into the suprachoroidal space in the operating room prior to the surgery. Another potential method for injecting r-tPA into the suprachoroidal 


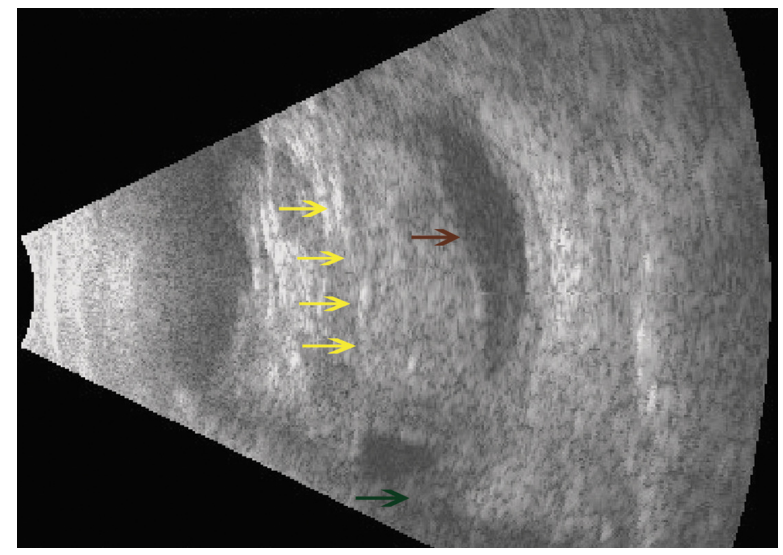

Figure I B-scan ultrasound image of a patient with extensive suprachoroidal hemorrhage secondary to tube shunt procedure treated with suprachoroidal $r$-tPA the day before surgery. Notice the dome shaped appearance and central apposition of detached choroid (yellow arrows). Shadow of glaucoma tube shunt (brown arrow). Optic nerve shadow (green arrow).

space preoperatively is using B-scan ultrasonography to guide the injection. This procedure is easier with two people, ie, one person holds the ultrasound probe (Figure 1), while the other performs the injection. The patient can then undergo the drainage procedure later that day or the following day.

In the experimental setting, a suprachoroidal hemorrhage is treated with intravenous or subconjunctival r-tPA..$^{21,22}$ Systemic tissue plasminogen activator is associated with significant systemic risks including intracranial hemorrhage..$^{23,24}$ Directly targeting the clot with suprachoroidal r-tPA, as in this case report, would aid in early liquefaction and allow for easier expression of the hemorrhage through sclerotomies regardless of the time of drainage, with fewer systemic consequences. Based on this case study, in which our patient had a fortunate outcome, it is our hypothesis that further study is warranted regarding the use of r-tPA in the treatment of suprachoroidal hemorrhage.

\section{Disclosure}

The authors report no conflicts of interest in this work.

\section{References}

1. Taylor DM. Expulsive hemorrhage. Am J Ophthalmol. 1974;78: 961-966.

2. Cantor LB, Katz LJ, Spaeth GL. Complications of surgery in glaucoma: Suprachoroidal expulsive hemorrhage in glaucoma patients undergoing intraocular surgery. Ophthalmology. 1985;92:1266-1270.

Clinical Ophthalmology

\section{Publish your work in this journal}

Clinical Ophthalmology is an international, peer-reviewed journal covering all subspecialties within ophthalmology. Key topics include: Optometry; Visual science; Pharmacology and drug therapy in eye diseases; Basic Sciences; Primary and Secondary eye care; Patient Safety and Quality of Care Improvements. This journal is indexed on PubMed

Submit your manuscript here: http://www.dovepress.com/clinical-ophthalmology-journal
3. Purcell JJ Jr, Krachmer JH, Doughman DJ, Bourne WM. Expulsive hemorrhage in penetrating keratoplasty. Ophthalmology. 1982;89: 41-43.

4. Wolter JR. Expulsive hemorrhage during retinal detachment surgery: A case with survival of the eye after Verhoeff sclerotomy. Am J Ophthalmol. 1961;51:264-266.

5. Winslow RL, Stevenson W IIIrd, Yonoff M. Spontaneous expulsive choroidal hemorrhage. Arch Ophthalmol. 1974;92:33-36.

6. Wirostko WJ, Han DP, Mieler WF, et al. Suprachoroidal hemorrhage: Outcome of surgical management according to hemorrhage severity. Ophthalmology. 1998;105:2271-2275.

7. Welch JC, Spaeth GL, Benson WE. Massive suprachoroidal hemorrhage. Follow-up and outcome of 30 cases. Ophthalmology. 1988;95: $1202-1206$.

8. Reynolds MG, Haimovici R, Flynn HW Jr, et al. Suprachoroidal hemorrhage. Clinical features and results of secondary surgical management. Ophthalmology. 1993;100:460-465.

9. Le MerY, RenardY, Allagui M. Secondary management of suprachoroidal hemorrhages. Graefes Arch Clin Exp Ophthalmol. 1993;231:351-353.

10. Lambrou FH Jr, Meredith TA, Kaplan HJ. Secondary surgical management of expulsive choroidal hemorrhage. Arch Ophthalmol. 1987;105: 1195-1198.

11. Campochiaro PA. Pathogenic mechanisms in proliferative vitreoretinopathy. Arch Ophthalmol. 1997;115:237-241.

12. Lakhanapal V. Experimental and clinical observations on massive suprachoroidal hemorrhage. Trans Am Ophthalmol Soc. 1993;91: $545-652$.

13. Becquet F, Caputo G, Mahhour B, et al. Management of delayed massive suprachoroidal hemorrhage. Eur J Ophthalmol. 1996;6:393-397.

14. Lakhanpal V, Schocket SS, Elman MJ, Nirankari VS. A new modified vitreoretinal surgical approach in the management of suprachoroidal hemorrhage. Ophthalmology. 1989;96:793-780.

15. Gressel MG, Parrish RK, Heuer DK. Delayed nonexpulsive suprachoroidal hemorrhage. Arch Ophthalmol. 1984;102:1757-1760.

16. Hoylaerts M, Rijken DC, Lijnen HR, Collen D. Kinetics of the activation of plasminogen by human tissue plasminogen activator. Role of fibrin. J Biol Chem. 1982;257:2912-2919.

17. Lambrou FH, Snyder RW, Williams GA. Use of tissue plasminogen activator in experimental hyphema. Arch Ophthalmol. 1987;105: 995-997.

18. Johnson RN, Olsen KR, Hernandez E. Intravitreal tissue plasminogen activator treatment of experimental vitreous hemorrhage. Arch Ophthalmol. 1989;107:891-897.

19. Oncel M, Peyman GA, Khoobehi B. Tissue plasminogen activator in the treatment of experimental retinal vein occlusion. Retina. 1989;9:1-7.

20. Johnson MW, Olsen KR, Hernandez E. Tissue plasminogen activator in the treatment of experimental subretinal hemorrhage. Retina. 1991;11: 250-258.

21. Kwon OW, Kang SJ, Lee JB, et al. Treatment of suprachoroidal hemorrhage with tissue plasinogen activator. Ophthalmologica. 1998;212:120-125.

22. Liu JC, Peyman GA, Oncel M. Treatment of experimental suprachoroidal hemorrhage with intravenous tissue plasminogen activator. Int Ophthalmol. 1990;14:267-270.

23. Elman MJ. Thrombolytic therapy for central retinal vein occlusion: Results of a pilot study. Trans Am Ophthalmol Soc. 1996;94: 471-504.

24. Hattenbach LO. Systemic lysis therapy in retinal vascular occlusions. Ophthalmologe. 1998;95:568-575. German.

\section{Dovepress}

Central and CAS, and is the official journal of The Society of Clinical Ophthalmology (SCO). The manuscript management system is completely online and includes a very quick and fair peer-review system, which is all easy to use. Visit http://www.dovepress.com/testimonials. php to read real quotes from published authors. 